\begin{tabular}{cc}
\hline International Journal of Advanced Astronomy, $8(1)(2020) 1-9$ \\
SPC \\
International Journal of Advanced Astronomy \\
Website: www.sciencepubco.com/index.php/IJAA \\
Research paper
\end{tabular}

\title{
SCINDA-GPS derived TEC depletions and amplitude scintillations over Kisumu, Kenya during selected quiet and storm days of 2013 and 2014
}

\author{
Uluma Edward $^{1 *}$, Ndinya Boniface ${ }^{1}$, Omondi George ${ }^{2}$ \\ ${ }^{1}$ Department of Physics, Masinde Muliro University of Science \& Technology, Kakamega, Kenya \\ ${ }^{2}$ Department of Physics and Materials Science, Maseno University, Maseno, Kenya \\ *Corresponding author E-mail: nyogesa_edward@yahoo.com
}

\begin{abstract}
Total Electron Content (TEC) depletion and amplitude scintillation $\left(\mathrm{S}_{4}\right)$ can be derived from, SCINDA-GPS receivers situated in various parts of the equatorial region. In this paper we present results of characterization of TEC depletions and amplitude scintillations over Kisumu, Kenya (Geomagnetic coordinates: $9.64^{\circ} \mathrm{S}, 108.59^{\circ} \mathrm{E}$; Geographic coordinates: $0.02^{\circ} \mathrm{S}, 34.6^{\circ} \mathrm{E}$ ) for both selected geomagnetically quiet and geomagnetically disturbed conditions between $1^{\text {st }}$ January 2013 and $31^{\text {st }}$ December 2014 using data derived from the Kisumu NovAtel GSV4004B SCINDA-GPS receiver situated at Maseno University. TEC depletions and amplitude scintillations affect Global Positioning System (GPS) signals in the ionosphere as they propagate from the satellite to the receiver. This study aims to investigate day to day variability of TEC depletions and amplitude scintillations over Kisumu, Kenya during both geomagnetically quiet and geomagnetically disturbed days of 2013 and 2014 which was a high solar activity period for Solar Cycle 24. Seasonal variability of TEC depletions and $S_{4}$ index is also presented. The Receiver Independent Exchange (RINEX) data for the years 2013 and 2014 was retrieved from the Kisumu SCINDA-GPS receiver, processed to obtain Vertical Total Electron Content (VTEC), $\mathrm{S}_{4}$ and Universal Time (UT) and fed into MATLAB to generate VTEC and $\mathrm{S}_{4}$ plots against UT for each selected quiet and storm day within the 2013 and 2014 period. The obtained results showed a diurnal variation of TEC where TEC was minimum at pre-sunrise, maximum during daytime and minimum during nighttime. The minimum TEC during pre-sunrise and nighttime was attributed to reduced solar intensity while maximum TEC during daytime is attributed to increased solar intensity. Most of the selected quiet and storm days of the years 2013 and 2014 showed TEC depletions and TEC enhancements corresponding with enhanced amplitude scintillations between 1800UT and 20:00UT. This might be attributed to the rapid rise of the F-layer and the increase in the vertical $\mathbf{E} \times \mathbf{B}$ plasma drift due to the Pre-reversal Enhancement (PRE) of the eastward electric field. Post-midnight TEC depletions and amplitude scintillations were observed for some days and this was attributed to the effect of zonal winds which brought post-midnight enhancement of the $\mathbf{E} \times \mathbf{B}$ drift. The percentage occurrence of amplitude scintillations for the selected quiet and storm days exhibited a seasonal dependence with equinoctial months having higher occurrences than the solstitial months. The higher average $S_{4}$ index during equinoctial months might be attributed to increased solar intensity resulting from the close alignment of the solar terminator and the geomagnetic meridian.
\end{abstract}

Keywords: Amplitude Scintillation; Geomagnetic Meridian; Solar Cycle 24; Solar Intensity; TEC Depletion.

\section{Introduction}

The ionosphere is the ionized portion of the atmosphere made up of positive ions and free electrons and it stretches from a height of about $50 \mathrm{~km}$ to $1000 \mathrm{~km}$ (Hunsucker \& Hargreaves, 1995; Misra \& Enge, 2001; Ndeda \& Odera, 2014). It consists of three layers which enable long distance radio wave propagation around the Earth (Rabiu et al., 2007; Milos, 2014). These layers are designated as: D-layer which lies within 50-90 km, E-layer which lies within 90-150 km and F-layer which lies within 150-1000 km from lowest to the highest. Signals from the GPS satellite pass through the ionosphere as they propagate towards the GPS receiver. The total number of electrons in a column of $1 \mathrm{~m}^{2}$ cross-section extending from a GPS receiver to a GPS satellite is known as TEC (Murkherjee et al., 2010; Adewale et al., 2012; Radicella, 2012; Ndeda \& Odera, 2014; Magdaleno et al., 2017). TEC is measured in TEC units (TECU) where 1 TECU is equal to $10^{16}$ electrons per $\mathrm{m}^{2}$. TEC depletions are sudden decreases in the TEC value lasting for about 10 to 60 minutes and are mostly followed by a TEC enhancement (a recovery of TEC) just after the depletion (Dashora \& Pandley, 2005). Increased solar activity can lead to large release of coronal mass ejections (CME) and solar flares that when they reach the Earth, can cause a change in TEC. Changes in TEC causes changes in the reflective properties of the ionosphere, storms and disruptions hence making GPS signals to suffer phase and amplitude deformation. Severe amplitude scintillations make the signals from the satellites to suffer loss of lock, leading to signal loss. 
Amplitude scintillation index is defined as the ratio of the standard deviation of signal intensity and the averaged signal intensity (Carrano, 2007) and given by equation below,

$$
S_{4}=\sqrt{\frac{\left\langle I^{2}\right\rangle-\langle I\rangle^{2}}{\langle I\rangle^{2}}}
$$

where, I represent the signal intensity (amplitude squared).

Various studies have been carried out on TEC depletions and amplitude scintillations over the equatorial region. Seemala and Valladares, (2011) studied TEC depletions over South America in 2008 using Low Latitude Ionospheric Network (LISN). TEC depletions having periods between 10 and 120 minutes were observed and were accompanied by stronger levels of scintillations. The characteristics of TEC depletion development were related with the onset of plasma bubbles in the equatorial F-layer after sunset. Olwendo et al., (2012) studied TEC depletions and enhancement over Kenya using SCINDA-GPS located at University of Nairobi (UoN) for March 2011. Their results showed TEC depletions having a good correspondence with $\mathrm{S}_{4}$ index patches. However, the observed TEC enhancements did not correlate with increases in $\mathrm{S}_{4}$ index. They interpreted TEC depletions as plasma irregularities and TEC enhancement as appearances of plasma density enhancements which were connected with the Equatorial Ionization Anomaly (EIA) crest over the region. D'ujanga \& Taabu, (2014) studied characteristics of ionospheric scintillations over East Africa using SCINDA-GPS and Very High Frequency (VHF) spaced receivers at UoN in 2011 and Makerere University in 2012. The percentage occurrence of scintillations at both frequencies exhibited a seasonal dependence: $S_{4}$ index were higher in equinoctial months than in other months. Intense scintillations were observed in 2011 than in 2012 and this was due to the intense geomagnetic storms and higher solar activity in October 2011. Akala et al., (2016) investigated GPS scintillation over Kampala, Uganda between 2010 and 2011 using SCINDA-GPS receiver. The results indicated that amplitude scintillations occurred mostly after sunset and decayed around midnight. Highest occurrence was in equinoctial months while low occurrence was in June solstice. Scintillation occurrences increased with increase in geomagnetic and solar activity. Muella et al., (2017) studied ionospheric scintillations at the equatorial anomaly crest region using a Global Navigation Satellites System (GNSS) station at Cachoera Paulista, Brazil between 1997 and 2014. The obtained results revealed maximum scintillation occurrence in the December solstice. This was attributed to a large magnetic declination angle over the region. The largest occurrence was $80 \%$ in $2001-2002$ (solar maximum of solar cycle 23) and began subsiding from 2002 to 2009 with decrease in solar activity. The decrease in frequency was due to the suppression of the fountain effect and the anomalous reduction in the background electron density observed at the EIA region. Alagbe et al., (2017) studied the effect of geomagnetic activity on amplitude scintillation in 2012 at low latitude region in Ilorin, Kwara state, Nigeria and observed that $\mathrm{S}_{4}$ occurrences were higher during quiet days than storm days. The $\mathrm{S}_{4}$ occurrences were seen to be enhanced during pre-midnight hours but were hindered during post-midnight hours for both quiet and storm days. This paper investigates TEC depletions and amplitude scintillations over Kisumu, Kenya for selected quiet and storm days of the years 2013 and 2014 . The average monthly and seasonal variation of TEC depletion and $\mathrm{S}_{4}$ index within the years 2013 and 2014 is also highlighted in this study.

\section{Materials and methods}

RINEX data archived in the SCINDA-GPS receiver between $1^{\text {st }}$ January 2013 and $31^{\text {st }}$ December 2014 was retrieved from the Kisumu NovAtel GSV4004B SCINDA-GPS receiver situated at Maseno University in Kenya. The obtained zipped RINEX data was unzipped using the WinRAR program and processed using Gopi Software to obtain a more simplified ten column daily file of ionospheric observables which included VTEC, $\mathrm{S}_{4}$ and UT.

To reduce multipath effects, the data selected in this study was of elevation angles of $40^{\circ}$ and above. The selected quiet days and storm days for the years 2013 and 2014 period of study were obtained from Dst index using data from the link: www.wdc.kug.kyotoua.ac.jp/dstdir. In this study, the quiet days considered were days having Dst index values $>-25 \mathrm{nT}$ while storm days were days having Dst index values $\leq-50 \mathrm{nT}$. The level of geomagnetic activity for the selected quiet and storm days was selected using the Kp index obtained from: www.kugi.kyoto-ua.ac.jp/kp, where the selected quiet days had Kp values between 0 and 2 while the selected storm days had Kp values between 3 and 9. The filtered average daily data of VTEC, $S_{4}$ and UT were obtained and were fed into MATLAB to generate VTEC and $\mathrm{S}_{4}$ plots for selected quiet and storm days of the years 2013 and 2014 as indicated in Figures 1, 2, 3 and 4. The obtained plots were used to investigate TEC depletions and amplitude scintillations over Kisumu, Kenya during selected quiet and storm days of the years 2013 and 2014. The average monthly TEC depletion and $S_{4}$ index were investigated and results summarized as indicated in Figure 5. Seasonal variation of TEC depletion and $S_{4}$ index were also investigated and results also summarized as in Figure 6.

\section{Results}

\subsection{TEC depletions and amplitude scintillations for selected quiet days of 2013}

Figure 1 shows VTEC and S4 plots for selected quiet days of the year 2013: 1(a)26 ${ }^{\text {th }}$ March 2013, 1(b) 18 ${ }^{\text {th }}$ April 2013, $1(\mathrm{c}) 19^{\text {th }}$ April 2013,1 (d) $10^{\text {th }}$ May 2013, 1(e) $17^{\text {th }}$ June 2013,1 (f) $26^{\text {th }}$ June 2013,1 (g) $4^{\text {th }}$ July 2013, 1(h) $24^{\text {th }}$ July 2013,1 (i) $11^{\text {th }}$ August $2013,1(\mathrm{j}) 7^{\text {th }}$ September 2013, 1(k) 26 $6^{\text {th }}$ September 2013 and 1(1)2 $1^{\text {st }}$ November 2013. Most of these selected quiet days of the year 2013 showed a minimum TEC during pre-sunrise hours (02:00-03:00 UT) with a magnitude of between 0-2 TECU. TEC was observed to rise steadily from 04:00 UT to around 12:00 UT where it attained maximum TEC value (45 -70 TECU) between 12:00-14:00 UT before reducing gradually up to 18:00 UT. From 18:00 UT, a TEC depletion depth of between 3 TECU and 25 TECU was attained before finally reducing to its minimum a few hours after sunset. The highest maximum TEC value (70 TECU) was attained on $21^{\text {st }}$ November 2013 as indicated in Figure 1(1). TEC depletion having large depletion depth (25 TECU) was on $19^{\text {th }}$ April 2013 as shown in Figure 1(c) while TEC depletions having smaller depletion depth (5 TECU) were observed on $26^{\text {th }}$ June 2013 as shown in Figure 1(f), $4^{\text {th }}$ July 2013 as in Figure 1(g), and $7^{\text {th }}$ September 2013 as shown in Figure 1(j). Figures 1(a), 1(b), 1(c), 1(d), 1(e), 1(g), 1(h), 1(k) and 1(l) has their TEC depletions corresponding with increased amplitude scintillations of more than 0.2 after sunset. The Figure 1(i) showed no TEC depletions with a slight increase in amplitude scintillation. 

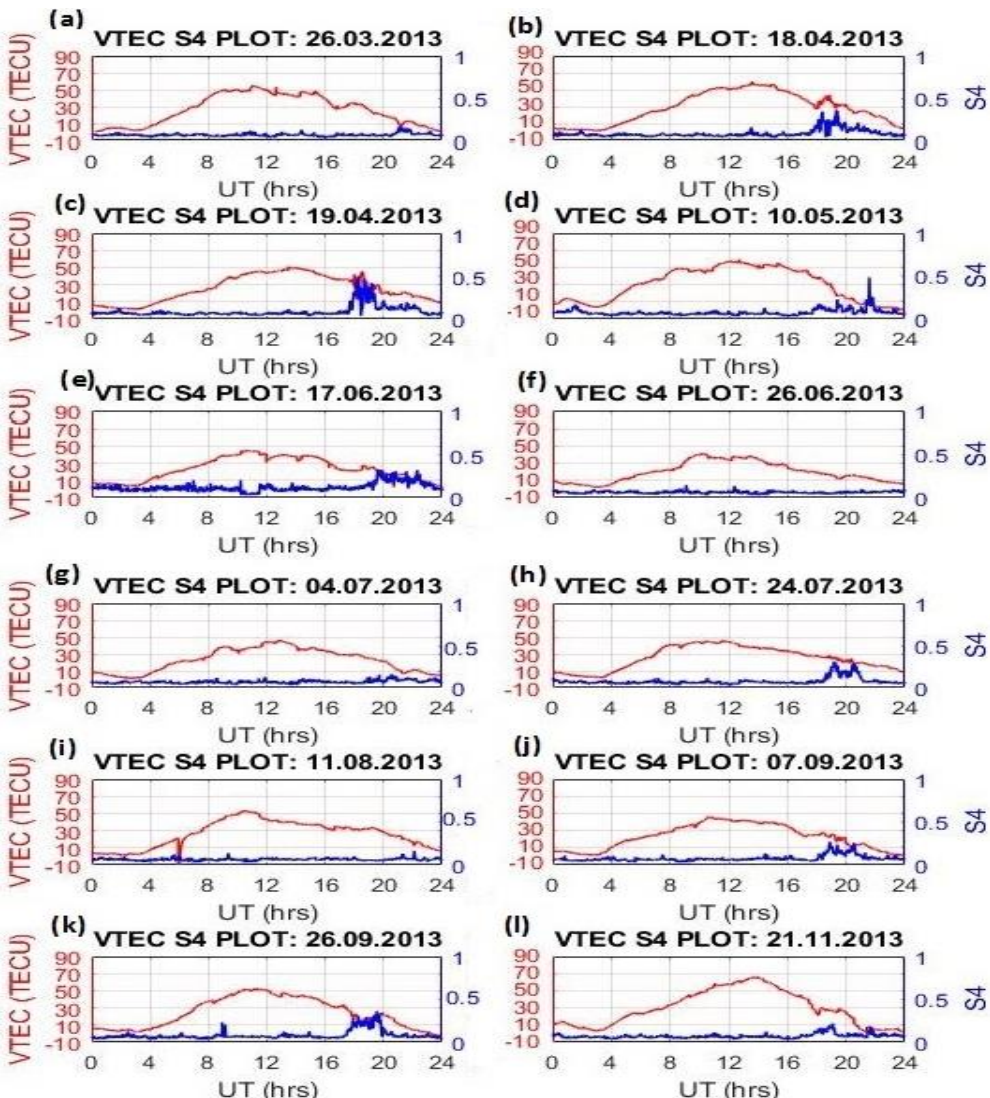

Fig. 1: VTEC and $\mathrm{S}_{4}$ Plots for: (a) 26-3-2013, (b) 18-4-2013, (c) 19-4-2013, (d) 10-5-2013, (e) 17-6-2013, (f) 26-6-2013, (g) 4-7-2013,(h) 24-7-2013, (i) 11-8-2013, (j) 7-9-2013, (k) 26-9-2013 and (1) 21-11-2013

\subsection{TEC depletions and amplitude scintillations for selected quiet days of 2014}

Figure 2 shows VTEC and $\mathrm{S}_{4}$ plots for selected quiet days of the year 2014: 2(a) $16^{\text {th }}$ January 2014,2 (b) $3^{\text {rd }}$ February 2014, 2(c) $7^{\text {th }}$ March 2014, 2(d) $16^{\text {th }}$ April 2014, 2(e) $2^{\text {nd }}$ May 2014, 2(f) $13^{\text {th }}$ May 2014, 2(g) $26^{\text {th }}$ August 2014, 2(h) $7^{\text {th }}$ September 2014, 2(i) $7^{\text {th }}$ October

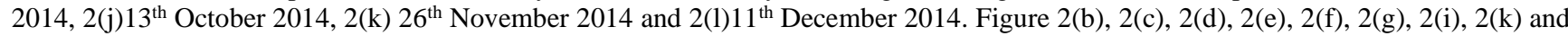
2(l) shows TEC depletions which corresponded with increased amplitude scintillation values of more than 0.3 after sunset. However, the TEC depletions on $16^{\text {th }}$ January 2014, $7^{\text {th }}$ September 2014 and $13^{\text {th }}$ October 2014 didn't correspond with amplitude scintillation increase as indicated in Figures 2(a), 2(h) and 2(j) respectively.

Most of these selected quiet days of 2014 showed a minimum TEC during pre-sunrise hours (02:00- 03:00 UT) with a magnitude of between 0-2 TECU. TEC was observed to rise steadily from 04:00 UT to around 12:00 UT where it attained maximum TEC value (50 70 TECU) between 12:00 -14:00 UT before reducing gradually up to 18:00 UT. From 18:00 UT, a TEC depletion depth of between 3 TECU and 20 TECU was attained before finally reducing to its minimum a few hours after sunset. The highest maximum TEC value (70 TECU) was attained on $7^{\text {th }}$ March 2014 as in Figure 2(c), 13 $3^{\text {th }}$ May 2014 as shown in Figure 2(f), $26^{\text {th }}$ August 2014 as shown in Figure $2(\mathrm{~g})$ and $26^{\text {th }}$ November 2014 as indicated in Figure 2(k). The largest TEC depletion depth $\left(20\right.$ TECU) was attained on $7^{\text {th }}$ Mach 2014 and $26^{\text {th }}$ August 2014 while the smallest depletion depth ( 3 TECU) was attained on $13^{\text {th }}$ October 2014.

Generally, it should be noted that the largest TEC depletion depth for the selected quiet days of the year 2013 and 2014 were on $19^{\text {th }}$ April 2013 (25 TECU) as indicated in Figure 1(c); 13 ${ }^{\text {th }}$ May 2014 (20 TECU) and 26 ${ }^{\text {th }}$ August 2014 (20 TECU) as indicated in Figures $2(\mathrm{c})$ and $2(\mathrm{~g})$ respectively and were likely attributed to the increased solar intensity: since the days fall in the equinoctial period. 


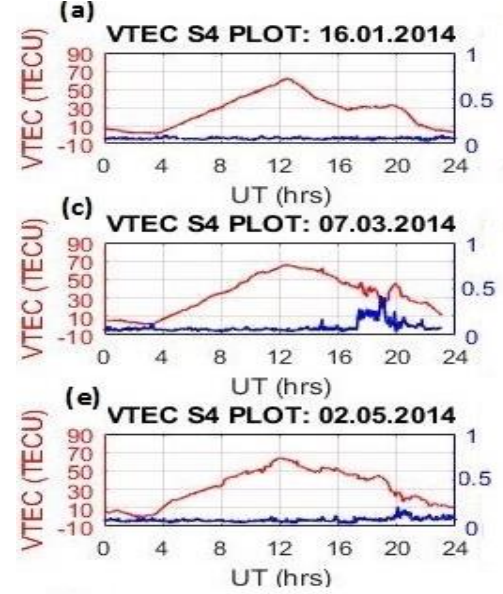

(g)
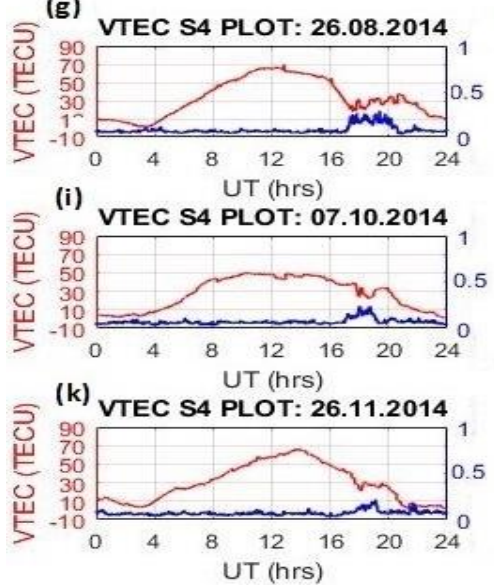

Fig. 2: VTEC and $\mathrm{S}_{4}$ Plots for: (a) 16-1-2014, (b) 3-2-2014, (c) 7-3-2014, (d) 16-4-2014, (e) 2-5-2014, (f) 13-5-2014, (g) 26-8-2014, (h)7-9-2014, (i)7-10-2014, (j)13-10-2014, (k) 26-11-2014 and (1) 11-12-2014

\subsection{TEC depletions and amplitude scintillations for selected storm days of 2013}

Figure 3 shows VTEC and $\mathrm{S}_{4}$ for selected storm days of the year 2013: 3(a) $1^{\text {st }}$ March 2013, 3(b) 24 $4^{\text {th }}$ April 2013, 3(c) $1^{\text {st }}$ May 2013, 3(d) $18^{\text {th }}$ May 2013, 3(e) $1^{\text {st }}$ June 2013, 3(f) $6^{\text {th }}$ June 2013 , 3(g) $10^{\text {th }}$ July 2013, 3(h) $14^{\text {th }}$ July 2013 , 3(i) $5^{\text {th }}$ August 2013, 3(j) $9^{\text {th }}$ November 2013, 3(k) $11^{\text {th }}$ November 2013 and $8^{\text {th }}$ December 2013. Figure 3(b), 3(c), 3(e), 3(i), 3(j) and 3(k) shows TEC depletions which corresponded with increased amplitude scintillation values of more than 0.2 after sunset. The TEC depletion on $1^{\text {st }}$ June 2013 and $6^{\text {th }}$ July 2013 didn't correspond with amplitude scintillation occurrence as indicated in Figures 3(e) and 3(f) respectively.

The selected disturbed days of 2013 showed a minimum TEC during pre-sunrise hours (02:00-03:00 UT) with a magnitude of between 0-2 TECU. TEC was observed to rise steadily from 04:00 UT to around 12:00 UT where it attained maximum TEC value (40-70 TECU) between 12:00 -14:00 UT before reducing gradually up to 18:00 UT. From 18:00 UT, a TEC depletion depth of between 2 TECU and 15 TECU was attained before finally reducing to its minimum a few hours after sunset. The highest maximum TEC value (70 TECU) was attained on $1^{\text {st }}$ May 2013 as shown in Figure 3(c), $9^{\text {th }}$ November 2013 as shown in Figure 3(j) and $11^{\text {th }}$ November 2013 as indicated in Figure 3(k).

The largest TEC depletion depth (16 TECU) was attained on $11^{\text {th }}$ November 2013 with a corresponding enhanced amplitude scintillation of about 0.2 as indicated in Figure 3(k) while the smallest TEC depletion depth ( 2 TECU) was attained on $14^{\text {th }}$ July 2013 with a corresponding enhanced amplitude scintillation index of about 0.3 as indicated in Figure 3(h). 

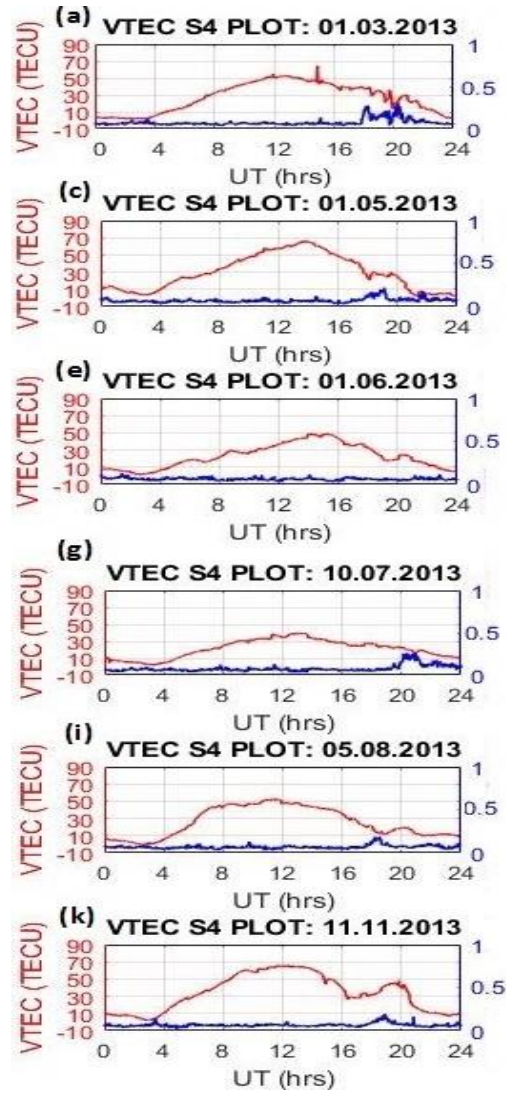

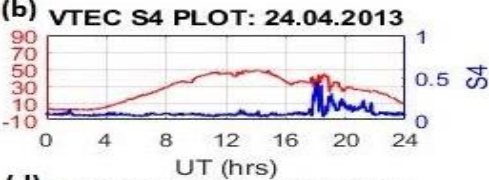

(d) VTEC S4 PLOT: 18.05 .2013
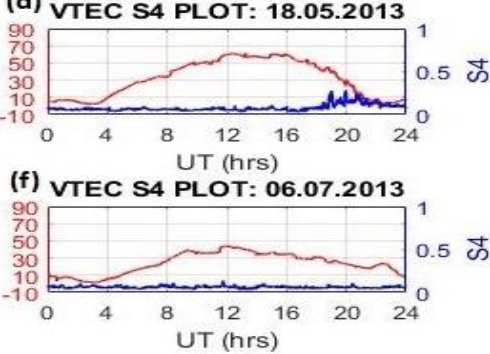

(h) VTEC S4 PLOT: 14.07 .2013

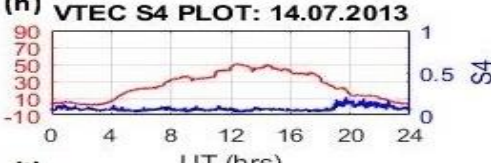

(j)

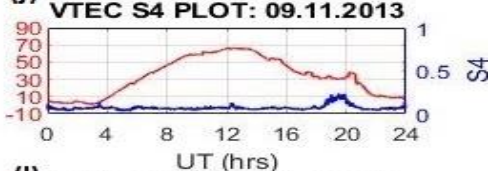

(I) VTEC S4 PLOT: 08.12.2013

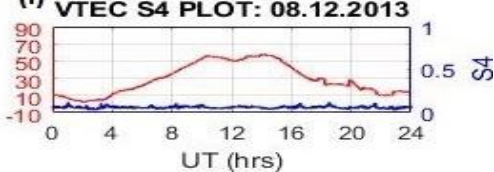

Fig. 3: VTEC and $S_{4}$ Plots for: (a)1-3-2013, (b)24-4-2013, (c)1-5-2013, (d)18-5-2013, (e)1-6-2013, (f)6-7-2013, (g) 10-7-2013, (h) 14-7-2013, (i) 5-8-2013, (j) 9-11-2013, (k) 11-11-2013 and (1) 8-12-2013.

\subsection{TEC depletions and amplitude scintillations for selected storm days of 2014}

Figure 4 shows VTEC and $\mathrm{S}_{4}$ plots for selected storm days of the year 2014: 4(a) $19^{\text {th }}$ February 2014, 4(b)20 $0^{\text {th }}$ February 2014, 4(c) $1^{\text {st }}$ March 2014, 4(d) $12^{\text {th }}$ April 2014, 4(e) $4^{\text {th }}$ May 2014, 4(f) $7^{\text {th }}$ June 2014, 4(g) $28^{\text {th }}$ August 2014, 4(h) 12 $2^{\text {th }}$ September 2014 and 4(i) $10^{\text {th }}$ November 2014.
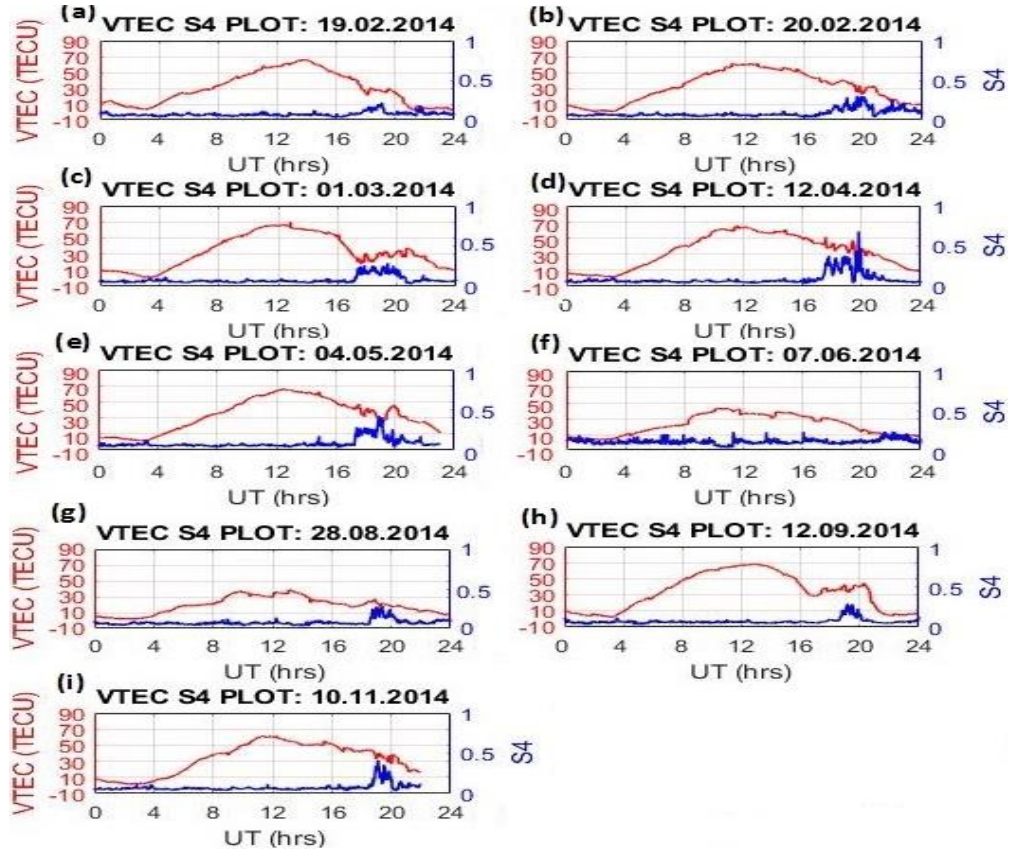

ॐ

Fig. 4: VTEC and $\mathrm{S}_{4}$ Plots for: (a) 19-2-2014, (b) 20-2-2014, (c) 1-3-2014, (d) 12-4-2014, (e) 4-5-2014, (f) 7-6-2014, (g) 28-8-2014, (h) 12-9-2014 and (i) 10-11-2014.

Figure 4(a), 4(b), 4(c), 4(d), 4(g), 4(h) and 4(i) shows TEC depletions which correspond with increased amplitude scintillation values of more than 0.2 after sunset.

For most of the storm days of 2014, TEC was minimum during pre-sunrise hours (02:00 UT- 03:00 UT) with a magnitude of about 4 TECU. TEC rose steeply between 03:00 UT -09:00 UT. It increased steadily from 10:00 UT to 12:00 UT where a maximum TEC of between 40-70 TECU was attained before beginning to decrease gradually up to 18:00 UT. TEC then increased by about 10-18 TECU before finally falling to its minimum a few hours after sunset. The largest maximum TEC value (70 TECU) was attained on $19^{\text {th }}$ February 
2014 and $12^{\text {th }}$ September 2014 as indicated in Figures 4(a) and 4(h) respectively. The largest TEC depletion depth (18 TECU) was attained on 1st March 2014 and 4th May 2014 as shown in Figures 4(c) and 4(e) respectively while the smallest TEC depletion depth (3 TECU) was attained on $7^{\text {th }}$ June 2014 as shown in Figure 4(f). The highest scintillation index attained was 0.7 on $12^{\text {th }}$ April 2014 as indicated in Figure 4(d).

The selected storm days of the year 2013 and 2014 had the largest TEC depletion depth on $11^{\text {th }}$ November 2013 (16 TECU), $1^{\text {st }}$ March 2014 (18 TECU) and $4^{\text {th }}$ May 2014 (18 TECU) as indicated in Figure 3(k), 4(c) and 4(e) respectively.

It is noted from the VTEC and $\mathrm{S}_{4}$ plots that TEC depletions and amplitude scintillations occurred after 17:00UT during both geomagnetically quiet and geomagnetically disturbed selected days of the years 2013 and 2014.

\subsection{Monthly average TEC depletion depth and amplitude scintillation index}
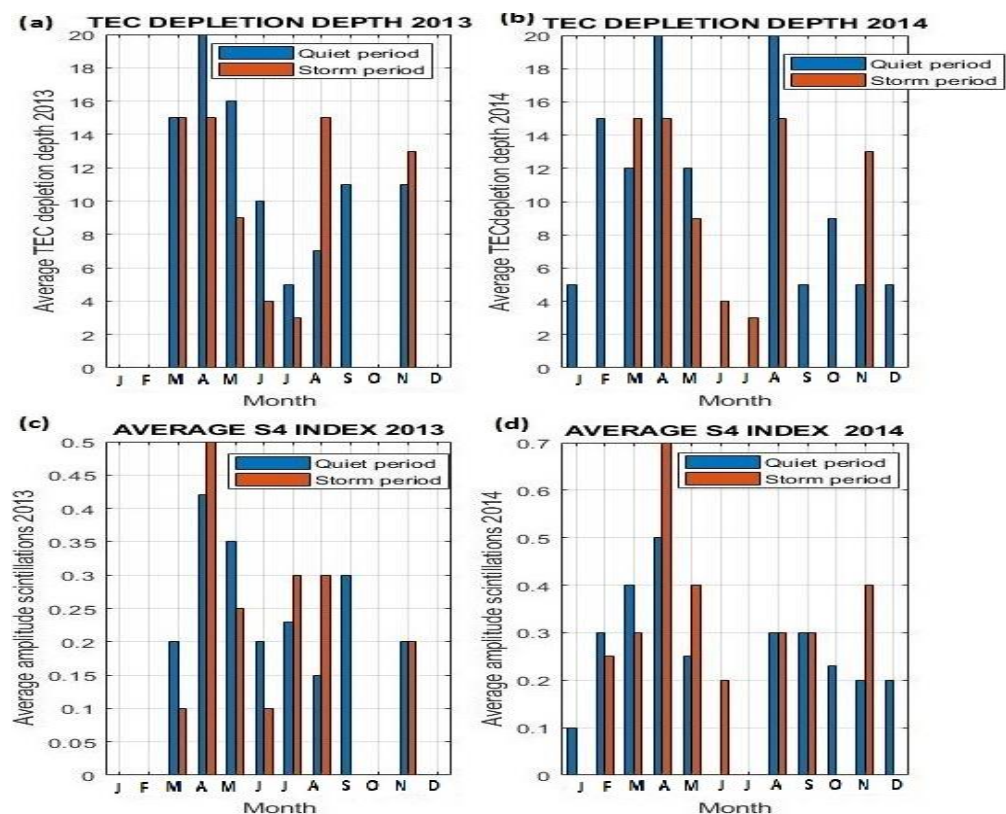

Fig. 5: Average Monthly TEC depletion depth for: (a) Year 2013, (b) Year 2014; Average Monthly $\mathrm{S}_{4}$ Index for: (c) Year 2013, (d) Year 2014

Monthly average TEC depletions and amplitude scintillations were analyzed for all the selected quiet and storm days and presented as shown in Figure 5. The months of January, February, March, April, May, June, July, August, September, October, November and December 2013 and 2014 have been represented as J, F, M, A, M, J, J, A, S, O, N and D respectively. The largest average TEC depletion depth was 20 TECU during the quiet period of April 2013 as indicated in Figure 5(a), quiet period of April 2014 as indicated in Figure 5(b) and quiet period of August 2014 as indicated in Figure 5(b) while the lowest average TEC depletion depth was 3 TECU observed during storm period of July 2013 and July 2014 as indicated in Figure 5(a) and 5(b) respectively. Similarly, the largest average monthly $\mathrm{S}_{4}$ index was 0.7 and was observed during storm period of April 2014 and $\mathrm{S}_{4}$ index of 0.5 in the storm period of April 2013 as indicated in Figures 5(d) and 5(c) respectively. However, the smallest average monthly $\mathrm{S}_{4}$ index of 0.1 was observed in a quiet period of January 2014 as indicated in Figure 5(d).

\subsection{Seasonal average TEC depletion depth and amplitude scintillation index}
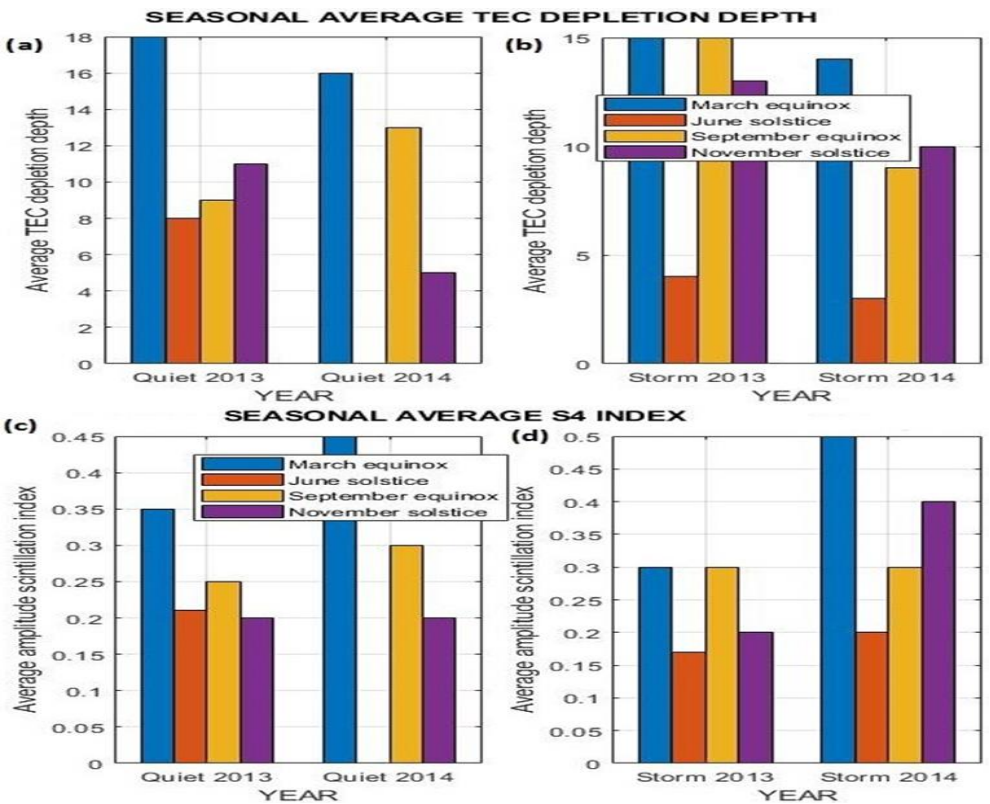

Fig. 6: Seasonal Average TEC depletion depth: (a) Year 2013, (b) Year 2014; Seasonal Average $\mathrm{S}_{4}$ Index: (c) Year 2013, (d) Year 2014. 
The average TEC depletion depth exhibited a seasonal dependence where the March equinox had the largest depletion depth of about 18 TECU for quiet period of the year 2013; 16 TECU for quiet period of the year 2014 and 15 TECU for storm period of 2013 as indicated in Figures 6(a) and 6(b). June solstice of the storm period of the year 2014 was seen to have the lowest average TEC depletion depth of about 3 TECU as indicated in Figure 6(b). The average occurrence of amplitude scintillations for the selected quiet and storm days also exhibited a seasonal dependence as indicated in Figure 6(c) and 6(d): the March equinox exhibited a higher average $\mathrm{S}_{4}$ index of about 0.35 for quiet period of the year 2013; 0.45 for the quiet period of the year 2014; 0.3 for the storm period of the year 2013 and 0.5 for the storm period of the year 2014) as indicated in Figures 6(c) and 6(d). The June solstice exhibited the lowest average $S_{4}$ index of about 0.15 for storm period of the year 2013 and 0.2 for storm period of the year 2014 as indicated in Figure 6(d).

\section{Discussion}

The VTEC and $\mathrm{S}_{4}$ plots for the selected quiet and storm days of the years 2013 and 2014 showed a diurnal variation with minimum TEC at pre-sunrise, maximum during daytime and at minimum during nighttime. This diurnal variation is attributed to variation of solar intensity at different hours of the day. The maximum TEC during daytime was attributed to increased ionization due to intense solar radiation while minimum TEC during pre-sunrise and nighttime was attributed to reduced solar radiation (Bolaji et al., 2012). This diurnal variation of TEC exhibits a similar trend to the one reported by Fayose et al., (2012) in their study on TEC variation and their effect on GNSS over Akure in Nigeria in 2010. All the selected quiet and storm days of the years 2013 and 2014 showed comparatively high maximum TEC values ranging between 40 and 70 TECU between 12:00UT and 14:00UT as indicated in Figures 1, 2, 3 and 4. The high TEC value is a reflection of the enhancement of Equatorial Ionization Anomaly (EIA) which has a main peak between 12:00 and 14:00UT and the secondary peak resulting from the pre-reversal enhancement. This variability of TEC ranging between 40 TECU and 70 TECU between 12:00UT and $1400 \mathrm{UT}$ might be attributed to the variation in the equatorial electric fields and the monthly solar flux. It was observed that for most of the selected storm and quiet days of the years 2013 and 2014, TEC depletions and TEC enhancements occurred consecutively and corresponded with increase in $S_{4}$ index after sunset as indicated in Figures 1(a), 1(b), 1(c), 1(d), 1(e), 1(g), 1(j), 1(k), 1(l), 2(b), 2(c), 2(d), 2(e), 2(f), 2(g), 2(i), 2(k), 2(l), 3(a), 3(b), 3(c), 3(e), 3(g), 3(h), 3(i), 3(j), 3(k), 4(a), 4(b), 4(c), 4(d), 4(e), 4(h) and 4(i). Bhuyan et al., (2007), associated these TEC enhancements with the secondary fountain effect resulting from occurrence of strong eastward electric field in the equatorial latitude after sunset. However, in this study, there are days where gradual decreases in TEC with very small recovery segments were observed. These days include: $26^{\text {th }}$ June 2013 as indicated in Figure 1(f), $14^{\text {th }}$ July 2013 as indicated in Figure 3(h), $13^{\text {th }}$ October 2014, as shown in Figure 2(j), $10^{\text {th }}$ July 2013 as indicated in Figure 3(g) and $7^{\text {th }}$ June 2014 as indicated in Figure 4(f). This might be attributed to the nighttime decay of the F-layer. It can also be observed that some of the selected storm days of 2013 and 2014 had their TEC enhancements appearing after more than 3 hours. These days include $16^{\text {th }}$ January 2014 as indicated in Figure 2 (a) and $11^{\text {th }}$ November 2013 as indicated in Figure 3(k). The reason for this might be due to the background electron density persisting for several hours after sunset. The highest $\mathrm{S}_{4}$ index attained for the selected quiet period was 0.5 on $19^{\text {th }}$ April 2013 and $16^{\text {th }}$ April 2014 as indicated in Figures 1(c) and 2(d) respectively. These days also happen to have the largest TEC depletion depth for the selected quiet and storm days of the years 2013 and 2014. We might attribute the high $\mathrm{S}_{4}$ index of 0.5 on these two days to the effect of increased solar intensity, since these two days lie in the March equinox. In this study, the highest scintillation index attained was 0.7 on $12^{\text {th }}$ April 2014 as indicated in Figure 4(d). This was a storm day having a minimum Dst index value of about -90nT and a Kp index value of 4 (Active storm). We might attribute this to the fact that solar cycle 24 reached its peak with a Smoothed Sunspot Number (SSN) of 81.9 in April 2014 (Schrodet et al., 2017). Kintner et al, (2009) reported that during solar maximum period, large mass ejections released from the Sun at a speed of about 1000 miles per second and accompanied by high intensity Ultra Violet (UV) radiations from the Sun causes severe perturbation to the electron density and homogeneity of the ionosphere. This magnifies the RTI on the bottomside of the F-layer of the ionosphere developing irregularities (Adewale et al., 2012).

Considering the daily average TEC values occurring between 12:00UT and 14:00UT for the years 2013 and 2014, it is should be noted that the daily average TEC values were highest during equinoctial months (March, April, August and September) with 59 TECU while lower TECU values were observed during solstitial months (June, July, November and December) with 55 TECU. These results are similar to those reported by Fayose et al., (2012) in a study of TEC variations over Akure, Nigeria in 2010 and Oron et al., (2013) in a study of TEC variation over Kampala, Uganda between 2010 and 2011, where the daily average TEC values were observed to be higher during equinoctial months and lower during solstitial months.

The amplitude scintillations exhibited a seasonal dependence with equinoxes recording higher amplitude scintillations than the solstices as indicated in Figure 6(c) and 6(d). These results are similar to those reported by D'ujanga \& Taabu (2014) in their study of ionospheric scintillations over East Africa and by Akala et al, (2016) in their study of GPS scintillations over Kampala in 2010 and 2011. The higher average $S_{4}$ index during equinoctial months was attributed to increased solar intensity resulting from the close alignment of the solar terminator and the geomagnetic meridian (Tsunoda, 1985). Comparing the selected quiet and storm days of 2013 and 2014 , the quiet days were found to have a lower average $S_{4}$ index than the storm days as indicated in Figures 5(c) and 5(d). The higher average $S_{4}$ index during storm days might be attributed to the effect of the geomagnetic storm which increased background ionization density of the ionosphere. However, the average $S_{4}$ index for the selected quiet and storm days of 2013 and 2014 were very low. This might have been due to the smaller number of sunspots in solar cycle 24, brought about by lower oxygen densities and a drop in the solar Extreme Ultra-Violet (EUV) flux, leading to a drop in the ionospheric densities in the EIA as observed by Muella et al, (2017).

The TEC depletions and amplitude scintillation events observed in this study for the selected quiet and disturbed days of 2013 and 2014 occurred majorly between 17:00UT and 20:00UT. This post-sunset occurrence of amplitude scintillations near the magnetic equator might have been brought about by the rapid rise of the F-layer and the increase in the vertical $\mathbf{E} \times \mathbf{B}$ plasma drift due to the Pre-reversal Enhancement (PRE) of the eastward electric field as reported by D'ujanga and Taabu, (2014). However, some days had TEC depletions and amplitude scintillations events occurring after mid-night. These days include: $10^{\text {th }}$ May 2013 as indicated in Figure 1(d), 1 $7^{\text {th }}$ June 2013 as indicated in Figure 1(e), $4^{\text {th }}$ June 2013 as indicated in Figure 1(g) and $11^{\text {th }}$ December 2014 as indicated in Figure 2(l). Studies done by de La Beaujardiere, (2009) showed large pre-dawn density depletions observed in the equatorial ionosphere below 550km. Huba et al, (2010) attributed these pre-dawn density depletions to the effect of zonal winds which brings post-midnight enhancement of the upward $\mathbf{E} \times \mathbf{B}$ drifts. 


\section{Conclusion}

TEC depletions and amplitude scintillation index over Kisumu, Kenya during selected quiet and storm days of the years 2013 and 2014 have been characterised and the obtained results have shown that TEC depletions and TEC enhancements corresponding with enhanced amplitude scintillations occurred between 17:00UT and 20:00UT over Kisumu, Kenya. Bhuyan et al, (2007) associated this TEC enhancement with the secondary fountain effect resulting from occurrence of strong eastward electric field in the equatorial latitude after sunset. D'ujanga and Taabu, (2014) associated the TEC depletions and enhanced amplitude scintillation events occurring majorly after 17:00UT due to the rapid rise of the F-layer and the increase in the vertical $\mathbf{E} \times \mathbf{B}$ plasma drift due to the PRE of the eastward electric field. Post-midnight TEC depletions and amplitude were also noted for some days and this was attributed to the effect of zonal winds which brings post-midnight enhancement of the upward $\mathbf{E} \times \mathbf{B}$ drifts.

On the monthly occurrence, April and August had the largest average TEC depletion depth for the years 2013 and 2014 while the months of June and July recorded the smallest average TEC depletion depth. Similarly, the highest average amplitude scintillation index was in April 2014 while the lowest average amplitude scintillation was in January 2014.

The occurrence of amplitude scintillations for the selected quiet and storm days exhibited a seasonal dependence with equinoctial months having higher occurrences than the solstitial months. The higher average $\mathrm{S}_{4}$ index during equinoctial months was attributed to increased solar intensity resulting from the close alignment of the solar terminator and the geomagnetic meridian (Tsunoda, 1985).

TEC depletions and amplitude scintillations showed a geomagnetic dependence. The quiet period exhibited larger TEC depletion depths than storm period. Similarly, high amplitude scintillations were recorded during storm period than quiet period of the years 2013 and 2014. The higher $\mathrm{S}_{4}$ occurrence during storm period might be attributed to the effect of storm brought by increase in background ionization density.

\section{Acknowledgements}

The authors thank Boston College and the Air Force Research Laboratory (AFRL), USA who supplied the Kisumu SCINDA-GPS receiver at Maseno University that was used to access the data used in this research. They are also grateful to Masinde Muliro University of Science and Technology (MMUST) for providing library and internet facilities while undertaking the research.

\section{References}

[1] Adewale, A. O.,Oyeyemi, E. O.,Adeloye, A. B.,Mitchell, C. N., Rose, J. A. R. and Cilliers, P. J. A (2012).Study of L-band scintillations and total electron content at an Equatorial Station. Lagos, Nigeria. Radio science, vol. 47, RS2011, https://doi.org/10.1029/2011RS004846.

[2] Akala, O. A., Idolor, R., D’ujanga, M., and Doherty, P. H. (2016). GPS-Amplitude Scintillation over Kampala during 2010-2011. Acta Geophysica, Vol. 64, no. 5, Oct. 2016,1903-1915 https://doi.org/10.1515/acgeo-2016-0052.

[3] Alagbe, G. A., Ofalabi, O. O., Adagunodo, T. A., Rabiu, S. B., Akinwumi, S. A. and Omotosho, T. V. (2017). Study of Ionospheric Amplitude scintillation during geomagnetic activities of 2012 at low latitude region. Vol. 9, No.2, pp251-256, 2017. ISSN 0975-5748.

[4] Bhuyan, P. K. and Borah, R. R. (2007). TEC derived from GPS network in India and comparison with the IRI. Adv. Space Res. 39, 830-840. https://doi.org/10.1016/j.asr.2006.12.042.

[5] Carrano, C. S. (2007). GPS -SCINDA: A real-time GPS data acquisition and ionospheric analysis System for SCINDA. Atmospheric and environmental Research, Inc., GPS-SCINDA.

[6] Dashora, N. and Pandley, R. (2005). Observations in the equatorial anomaly region of total electron content enhancements and depletions. Ann. Geophys.23,2449-2456. https://doi.org/10.5194/angeo-23-2449-2005.

[7] De La Beaujardiere, O. (2009). C/NOFS observations of deep plasma depletions at dawn, Geophys. https://doi.org/10.1029/2009GL038884 Res. Lett., 36, LOOC06, https://doi.org/10.1029/2008JA013668.

[8] D'ujanga, F. M. and Taabu, S. D. (2014) Study on the occurrence characteristics of VHF and L-band ionospheric Scintillations over East Africa. Indian Journal of Radio and space physics. PACs No.94.20wg; 94.20. VV, Vol. 43,263-273, 2014. https://doi.org/10.1016/j.habitatint.2014.04.008.

[9] Fayose, R.S., Oladosu, O.R., Rabiu, A.B. and Grooves, K. (2012). Variation of Total Electron Content [TEC] and their Effect on GNSS over Akure, Nigeria. doi:10.5539/apr.v4n2p105. https://doi.org/10.5539/apr.v4n2p105.

[10] Huba, J. D., Joyce, G., Krall, C. L.,Siefring, C. L. and Bernhardt, P. A. (2010).Self-consistent Modelling of equatorial dawn density depletions with SAM13, Geophys. Res. Lett., 37, L033140, https://doi.org/10.1029/2009GL041492.

[11] Hunsucker, R. D. and Hargreaves, J. K. (1995). The high latitude Ionosphere and its effect on Radio propagation.Cambridge University Press

[12] Kintner, P.M., Ledvina, B.M. and de Paula, E. R. (2007). GPS and ionospheric scintillations. Space Weather 5, S09003, https://doi.org/10.1029/2006SW000260.

[13] Magdaleno, S., Herraiz M., Altadill, D. and De la Morena. (2017). Climatology characterization of equatorial plasma bubbles using GPS data.J. Space Weather Space Clim,7 A3 (2017). https://doi.org/10.1051/swsc/2016039.

[14] Milos, M. (2014). Determination of TEC in the ionosphere using GPS Technology. Vol. 2, No. 2, Doi: 10.144 38/gn.2014.22.

[15] Misra, P. and Enge, P. (2001). Global positioning system signals, measurements and performance. Ganga-Jamuna press, Lincoln,Massachusetts, USA.

[16] Muella, M. T. A. H., Duarte-Silva, M. H., Moraes, A. O., de Paula E. R., de Rezende, L. F. C., Alfonzi, L. and Affonso, B. J. (2017). Climatology and modeling of ionospheric scintillations and irregularity zonal drifts at the equatorial anomaly crest region. https://doi.org/10.5194/angeo-351201-2017.Ann. Geophys., 35, 1201-1218, 2017. https://doi.org/10.5194/angeo-35-1201-2017.

[17] Mukherjee, S., Sarkar, S., Purohit, P. K., and Gwal, A. K. (2010). Seasonal variation of Total Electron Content at crest of equatorial anomaly station during low solar activity conditions, Adv. Spac Res., 46, 291-295,2010. https://doi.org/10.1016/j.asr.2010.03.024.

[18] Ndeda, O. H., and Odera, P. O. (2014). Analysis of Longitudinal Advancement of the peak Total Electron Content in the African equatorial anomaly region using data from GPS receivers and GIS stations in Kenya, Canadian centre of Sc. \& Educ. Applied https://doi.org/10.5539/apr.v6n1p19. Phys. Research: vol. 6, No. 1; 2014. Doi: 10.5539/apr. V6n.1p.19.

[19] Olwendo, J. O., Cilliers, P. J., Baki, P. and Mito, C. (2012). Using GPS-SCINDA observations to study the correlation between scintillation, total electron content enhancement and depletions over the Kenyan region: Advances in Space Research 49 (2012) 1363-1372. https://doi.org/10.1016/j.asr.2012.02.006.

[20] Oron, S., D'ujanga, F. M. and Sssengonga J. J. (2013). Ionospheric TEC variations during the ascending solar activity phase at an equatorial station in Uganda. Ind. J. Radio space phys.42, 1, 7-17.

[21] Rabiu, A. B., Mamukuyomi A. I., and Joshua E. O. (2007). Variability of equatorial ionosphere inferred from geomagnetic field measurement. Bulletin astronomy society India, 37, 51-62, 2007.

[22] Radiciella, S. (2012). Workshop on science applications of GNSS in developing countries (11-27 April) followed by the Seminar on Development and use of ionospheric Ne Quick model 30th April -1st May 2012. 
[23] Schrodet, K. P., Mittag, M., Jack D., Schimit, J. H., Hempelmann, A. and Gonzalez-Perez, J. N. (2017). Carrington cycle 24: The solar chromospheric emission in a historical and stellar Perspective. Advance Access publication. MINRAS 470, 276-282(2017) Doi:10.1093/mnras/stx147. https://doi.org/10.1093/mnras/stx147.

[24] Seemala, G.K. and Valladares, C.E. (2011). Statistics of total electron content depletions observed over the South American continent for the year 2008. Radio Sci. 46, RS5019, https://doi.org/10.1029/2011RS004722.

[25] Tsunoda, R. T. (1985). Control of seasonal and longitudinal occurrence of equatorial scintillation by longitudinal gradient in integrated E region pederson conductivity, J. Geophys, Res. 90, A1., 447-456, https://doi.org/10.1029/JA090iA01p00447. 